\title{
When is it time to say enough is enough for historical mine rehabilitation and closure? A Pilbara case study
}

\author{
SJ Finucane Bioscope Environmental Consulting Pty Ltd, Australia \\ B Bastow Integrate Sustainability Pty Ltd, Australia
}

\begin{abstract}
Mine rehabilitation and closure standards, and stakeholder expectations regarding these, have changed significantly over time. In particular, over the last 20 years, regulator, community and industry expectations on what constitutes acceptable rehabilitation and walk-away solutions have increased dramatically. This has improved rehabilitation and closure outcomes, but this has also raised the bar to an often unrealistic level for historical mine sites. It can increase closure costs, prolong (or even prevent) site relinquishment and damage stakeholder confidence in a company's and the broader industry's ability to undertake mining in a sustainable manner. Is it fair to expect a historical site to meet modern standards or are these expectations setting up operations and companies to fail?

The imposition of current or future closure standards on older operations is a major concern for industry. There is a need for a new approach and dialogue regarding the actual environmental and community risks associated with historical sites, and what rehabilitation and closure standards are practical and should apply. If there are no sensitive receptors and the risks have been contained or are being managed effectively, why go any further? This does not mean that mine operators should ignore their responsibilities and that new mines should not be expected to achieve higher standards or best practice, but decisions need to be made on the most practical, pragmatic and cost-effective way to utilise what are often limited resources in rehabilitating and closing historical mines. To adopt a new approach, it is important that stakeholders understand the standards that were applied when mining at a site commenced and/or when a mine was operational, and what closure outcomes are realistic. Perhaps there are alternative, and possibly better, environmental outcomes that can be achieved rather than trying to achieve the impossible on a site that was not set up to current-day standards?
\end{abstract}

This paper discusses the Blue Spec Shear Gold-Antimony Project near Nullagine, Western Australia, and draws on other examples, to trigger a conversation within industry, regulators and the community about whether historical sites can meet modern rehabilitation and closure standards, and if a new site relinquishment approach is required.

\section{Introduction}

In its toolkit for planning integrated mine closure published a decade ago, the International Council on Mining \& Metals (ICMM) concluded that "Mine closure today is less of a technical challenge and more of a management challenge. Challenges around physical closure have been replaced by challenges regarding the nature and acceptance of closure outcomes and the ability to 'operationalize' the process of arriving at acceptable closure outcomes by integrating closure considerations with everyday business practices" (ICMM 2006, p. 49). This is certainly the case for contemporary mines where integrating mine closure into project planning and execution is now generally common practice. However, significant technical, ethical and other challenges arise when closing older and historical mines. This is particularly the case for an operation where little or no effort was allocated to plan for closure, let alone operationalise the process.

The Blue Spec Shear Gold-Antimony Mine is one such mine which operated at a time where there was little or no focus on mine site rehabilitation and closure. The mine is located approximately $18 \mathrm{~km}$ east-northeast of Nullagine and $180 \mathrm{~km}$ north of Newman in Western Australia (Figure 1). 


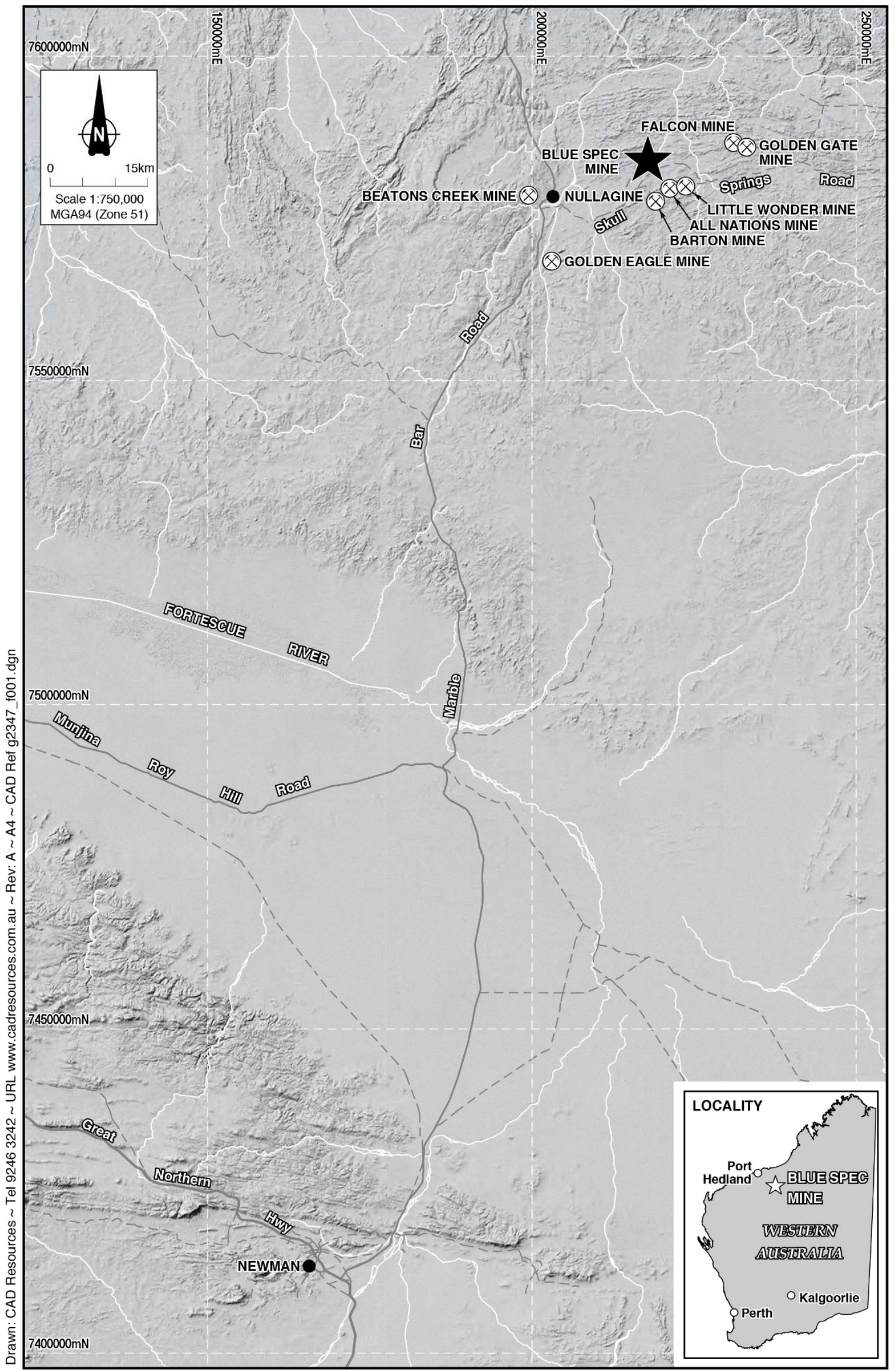

Figure 1 Location of the Blue Spec Mine site in Western Australia 
Exploration associated with the Blue Spec Gold-Antimony Mine commenced in 1906 and mining has occurred on a discontinuous basis since 1935. A number of mining disturbances are present at the site, including potentially contaminated areas. In 2009, Northwest Resources Limited (NWR) commissioned Bioscope Environmental Consulting Pty Ltd to assist it in the concurrent development of environmental permit applications and a mine closure plan (MCP). Conducting these work programmes in parallel was a deliberate company decision as it was recognised that thinking about the end before the start of operations would maximise opportunities to identify practical closure strategies, reduce closure costs and facilitate tenement relinquishment when this was required. However, the company was cognisant that there were significant challenges associated with remediation and closure of a mine that had operated under different environmental standards which were not likely to align with modern environmental standards and expectations. Therefore, there are a number of key questions that need to be addressed during the mine's closure planning process. These include the following:

- What environmental legacies exist at the site and how significant are these issues? To maximise opportunities for progressive remediation and rehabilitation during operations, how should site clean-up, rehabilitation and closure works be prioritised?

- Given the closure challenges and rehabilitation limitations associated with the site, is it realistic to expect the site to meet modern rehabilitation and closure standards? What would be reasonable and practical in terms of closure objectives?

- Where does responsibility lie for historical disturbances at the mine and where should it sit following tenement relinquishment?

- How should the mining company engage with regulators and other stakeholders in relation to the development and application of practical closure standards?

This paper discusses the questions listed above and considers when it is time to say enough is enough for historical mine rehabilitation and closure.

\section{History of the Blue Spec Gold-Antimony Mine}

The Blue Spec Gold-Antimony Mine comprises two deposits: Blue Spec and Gold Spec (Figure 2). The Blue Spec deposit was discovered in 1906 and was named after the winner of the 1905 Melbourne Cup. The mine first went into production in 1935 with the formation of the Blue Spec Mining Company NL and was subsequently operated by a succession of private syndicates. However, mining at Blue Spec was a difficult proposition due to a lack of water and capital, the poor availability of labour at mine sites remote from Kalgoorlie (particularly during the war years), the high cost of mining narrow stopes with hand-held machines and low gold prices (NWR 2015). Consequently, the mine operated only periodically until it closed in 1962.

Anglo American (Anglo) acquired the Blue Spec property in 1973. This was the first Australian project for the company, who operated the mine for 22 months between 1976 and 1978 . Access to the ore body was established via a decline and a new shaft sunk to a vertical depth of $190 \mathrm{~m}$. Anglo's processing plant was designed to separate the gold and antimony, and maximise gold recovery to doré. Tailings from the plant were discharged to the Anglo tailings storage facility (TSF) located approximately $250 \mathrm{~m}$ north of the plant. Mining proceeded to a vertical depth of $310 \mathrm{~m}$, but the complex nature of auro-stibnite ores resulted in very poor metal recoveries and the mine closed in 1978. Blue Spec has not been re-opened since that time (NWR 2015).

Gold mineralisation at Gold Spec was first intersected in 1956. Exploration occurred until 1968 when a small exploration shaft was sunk to a vertical depth of $44 \mathrm{~m}$. However, no mining developed occurred at Gold Spec until 1986 when the site was acquired (along with the Blue Spec property) by a joint venture (JV) between Minproc, Chase Minerals and Invincible Mining. The JV extended the existing shaft at Gold Spec to a vertical depth of $120 \mathrm{~m}$ to establish access to the deposit's east shoot with stoping occurring from around 
$102 \mathrm{~m}$ nearly to surface. The JV also established a small open pit at Gold Spec's west shoot and subsequently established a small shaft with a vertical depth of $50 \mathrm{~m}$ (NWR 2015).

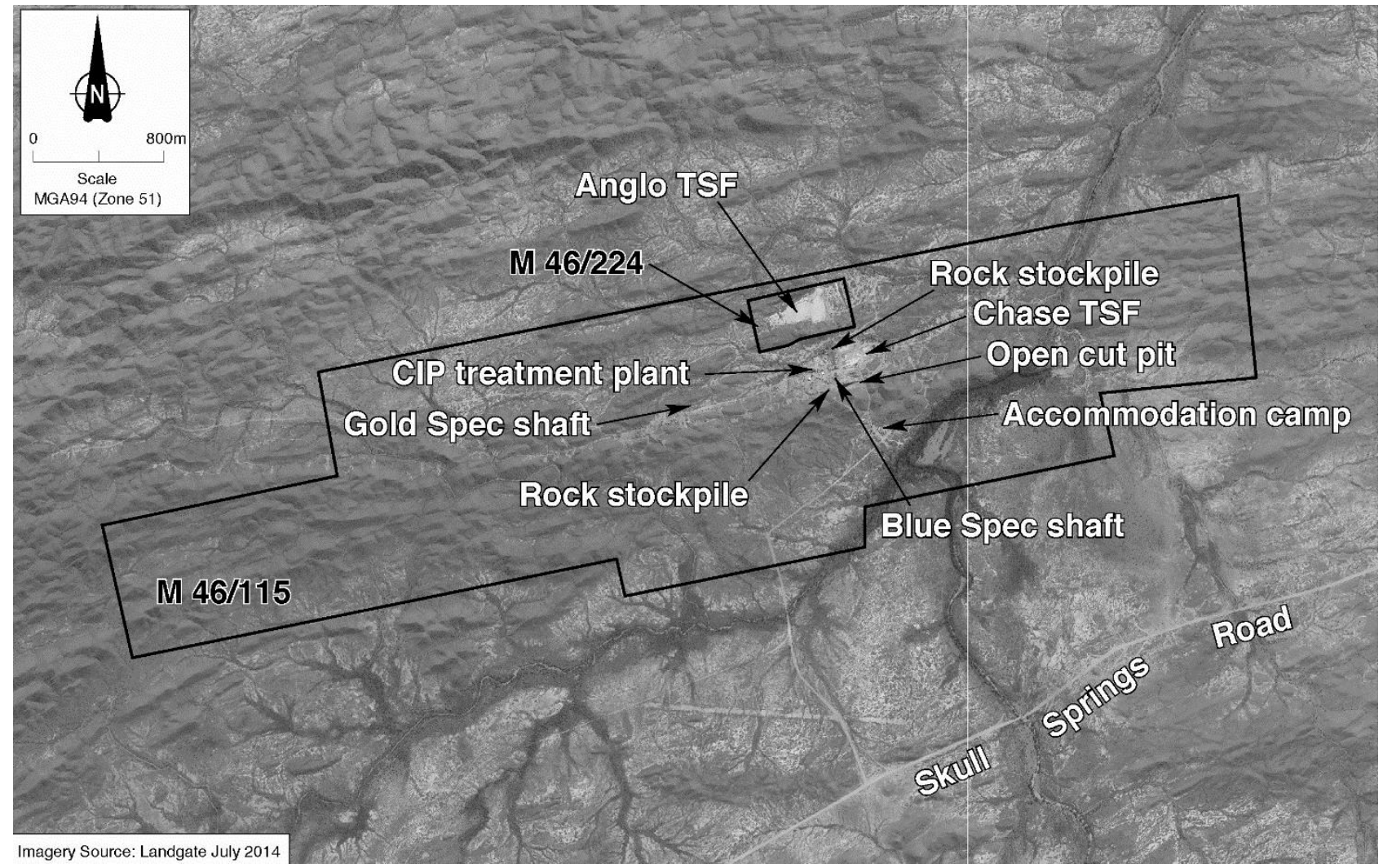

\section{Figure 2 Site tenure and layout of the Blue Spec Mine Site}

In 1986, the Anglo Blue Spec processing plant was dismantled and a new Carbon-in-Pulp (CIP) treatment plant was constructed by Minproc to process ore from Gold Spec. Like its predecessor, this plant was designed to maximise gold recovery to doré, but a new process flow was adopted whereby antimony was floated off prior to leaching the gold. Anecdotally, the plant achieved good recoveries of gold at the expense of antimony, but it is understood that the plant never operated to specification (NWR 2015). The plant discharged tailings to a small five-celled TSF known as the Chase TSF.

Chase Minerals bought out its JV partners in 1988 but went into administration while attempting to raise further funds for the development of Gold Spec. The property was subsequently acquired from the administrator and operated for a period of 13 months in 1991 to 1992. Development at Gold Spec during this period included establishment of a drive between the east and west shoots at the $120 \mathrm{~m}$ level and stoping on the west shoot. Gold Spec has not operated since that time.

No mine site rehabilitation was conducted at either Blue Spec or Gold Spec by previous tenement holders. As a result of these historical activities, the mine has a footprint of approximately 111 ha over a number of tenements including two mining leases (M46/115 and M46/244), (Figure 2). Existing disturbances within the mining leases include:

- A small open cut pit, underground shafts and associated mining infrastructure.

- The CIP treatment plant where reagents and other chemicals have been stored and used in the past.

- The Anglo TSF, which is the larger of the two TSFs at the mine. This facility is located within M46/244 and covers an area of approximately $100,000 \mathrm{~m}^{2}$. The embankment of this TSF was breached in 1997 and 2002, resulting in the migration of tailings up to $350 \mathrm{~m}$ down-gradient. 
- The smaller Chase TSF. This facility is located within M46/115 and consists of five main storage cells. Tailings have been washed downslope from the TSF.

- A landfill trench to the east of the Anglo TSF.

- An accommodation camp and other supporting infrastructure.

The Anglo and Chase TSFs were not capped or rehabilitated by previous operators and tailings have migrated down-gradient from these facilities. Consequently, tenements M46/115 and M46/244 have been classified under the Western Australian Contaminated Sites Act 2003 as "Potentially Contaminated Investigation Required" due to the migration of tailings from the TSFs.

NWR acquired the Blue Spec and Gold Spec properties in December 2004. In 2009, the company commenced a range of environmental studies and initiated preparation of environmental permit applications for mining and processing at Blue Spec. Tenement conditions require the preparation of a MCP so closure planning for the mine also commenced.

In August 2015, NWR entered into an agreement to sell the project to Beatons Creek Gold Pty Ltd (BCG), a subsidiary of Novo Resources Corp (Novo). Completion of the sale occurred in October 2015, Novo's Beatons Creek Gold Project is located $20 \mathrm{~km}$ west of the Blue Spec Gold-Antimony Mine (Figure 1).

The following sections describe the work completed to date for Blue Spec in relation to the four questions identified in Section 1.

\section{Hazard predisposition}

In general, a mine that closes in current times is required to be safe, stable and non-polluting, and be able to sustain the nominated post-mining land use(s). However, regulations in the past were weaker and community expectations were lower, which have contributed to the existence of mines that do not meet today's standards (Unger 2014). Of course, not all historical mines are problematic. For example, of an estimated 100,000-500,000 small and medium-sized abandoned hard rock mines sites in North America, only $1-2 \%$ present an environmental risk (primarily in the form of water pollution) and only $5-10 \%$ are considered to be hazardous from a health and safety perspective (Environment and Security Initiative 2005). Therefore, it was important to understand the type, extent and significance of the environmental and other issues present at a mine site and how these can affect mine closure planning and site relinquishment.

As outlined in Section 2, the Blue Spec mine site has been disturbed as a result of historical exploration and mining activities. Therefore, an assessment of existing environmental legacies and potential environmental hazards was undertaken early to obtain a clear understanding of issues to be addressed in closure planning for the site. Key to this assessment (and to later stakeholder engagement) was recognition that not all disturbances necessarily constitute a hazard to the natural or social environment. Didier et al. (2009) note that a hazard is defined by the probability of occurrence and foreseeable magnitude of an event at a specific location. Probability of occurrence is generally more difficult to quantify than magnitude as it is influenced by a wide range of factors including a site's sensitivity subject to instability, the complexity of the mechanisms involved, heterogeneity in the environment and completeness of datasets. Consequently, it can be very difficult to determine quantitative probabilities. Therefore, priority is often placed on assessing a site's qualitative predisposition to hazards (Didier et al. 2009). Factors influencing hazard predisposition vary within and between sites, and include time, water, geology and mining methods (Didier et al. 2008).

Assessment of environmental hazards often commences with a desktop review of existing information which can provide an invaluable understanding of how issues arose during previous mining operations and what to expect in relation to current conditions at site. However, there had been poor retention of site data and other information for the Blue Spec mine. Therefore, to better understand the mine's existing environmental legacies and its predisposition to future hazards, NWR commissioned a preliminary site 
investigation (PSI). The PSI was conducted in August 2011 and identified areas that contained Contaminants of Potential Concern (CoPCs) including hydrocarbons, solvents and certain metals including antimony (URS 2012). The presence of these CoPCs was unsurprising given the site's operational history and the nature of local geology and other environmental features.

Potential receptors were identified in the PSI, but it was noted that these would only be considered as sensitive receptors if complete exposure pathways were present to link these with the source of the CoPCs. A number of potential pathways were identified including vertical seepage into shallow soils, surface water infiltration leading to vertical or lateral leaching of CoPCs within shallow soils to groundwater, and lateral migration of groundwater offsite into an adjacent drainage line (URS 2012).

Following integration of available data and development of a preliminary Conceptual Site Model (CSM), a Sampling and Analysis Plan (SAP) was developed for the site (URS 2012). The SAP outlined a sizeable programme of work that was comprehensive but exceeded company resources. Consequently, a Contaminated Sites Strategic Analysis (CSSA) was commissioned to document a road map that outlined how the required investigations could be staged across all phases of project development from pre-construction to closure without compromising the NWR's legal and other requirements and commitments (SRK Consulting 2012).

The objective of the CSSA was to provide a pragmatic and fiscally-reasonable investigation and reporting schedule for areas where CoPCs had been identified. Figure 3 provides an overview of the key components and expected outputs of the CSSA.

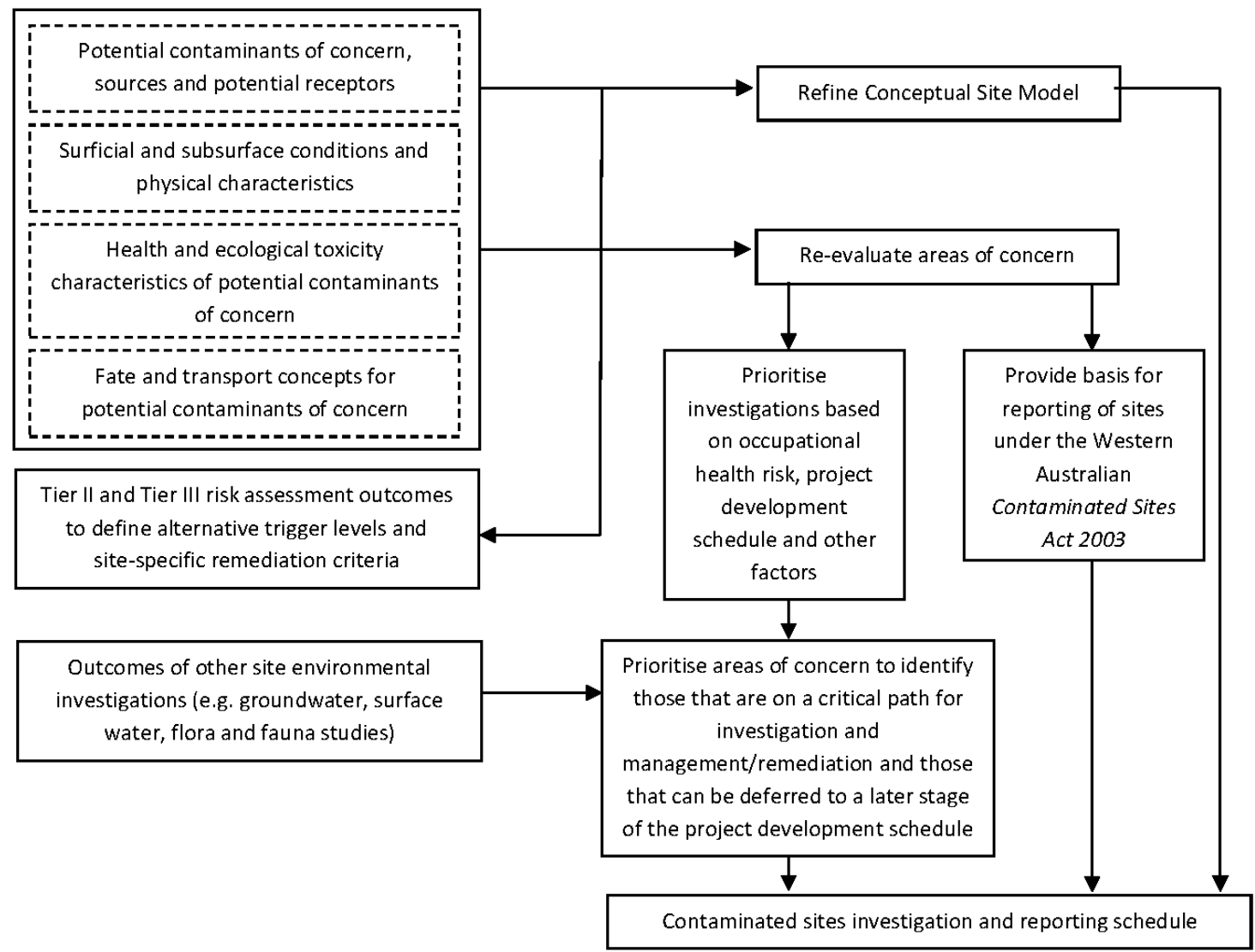

Figure 3 Key components of the contaminated sites strategic analysis (modified from SRK Consulting 2012)

Fundamental to this assessment was recognition that, for a site to be considered as contaminated under the Western Australian Contaminated Sites Act 2003, there needs to be a risk to human health and/or the natural environment that has either materialised (a legacy issue) or has the potential to materialise (hazard predisposition) (SRK Consulting 2012). In essence, the presence of CoPCs alone is not sufficient for a site to 
be classed as contaminated; there also needs to be a sensitive receptor and a complete exposure pathway. Further, it was recognised that not all CoPCs carry the same degree of significance. On this basis, a series of priority measures, based on the project development schedule, location of proposed site activities and receptors of immediate concern, was used to define an indicative contaminated sites investigation schedule. This schedule prioritised investigations of areas such as TSFs and CIP treatment plant over areas where CoPCs of less concern were present.

A fundamental question during the CSSA was, if there are no sensitive receptors and/or the hazards have been contained or are being managed effectively, why go any further? This does not mean that mine operators should ignore their responsibilities, but that decisions need to be made on the most practical, pragmatic and cost-effective way to rehabilitate and close an old mine. To respond to this question, it was proposed that a Tier II risk assessment be conducted to allow development of generic response (or trigger) levels which more closely reflect the Blue Spec exposure scenario and a Tier III risk assessment to develop site-specific levels where generic levels were not available or appropriate.

Tier II and III risk assessments are conducted if a Tier I screening risk assessment identifies unacceptable risks or if significant uncertainties exist (DER 2014). Tier I and Tier II assessments are based on generic assessment levels whereas a Tier III assessment uses site-specific data which reduce the level of uncertainty and may result in less conservative exposure assumptions being adopted (DER 2014). In turn, these assumptions may result in site-specific risk-based criteria that correspond to higher concentrations of contaminants than the generic assessment levels used for screening purposes, but which still protect human health, the environment and environmental values (DER 2014).

The outcome of these risk assessments provides a sound basis for discussions with regulators and other stakeholders in relation to what closure outcomes are realistic, the nature of risk associated with these outcomes and the closure standards that should be applied.

\section{$4 \quad$ The need for pragmatic closure objectives}

Before closure criteria can be developed, it is necessary to identify the post-mining land use(s) and closure objectives. The Western Australian Guidelines for Preparing Mine Closure Plans prepared by the Department of Mines and Petroleum (DMP) and Environmental Protection Authority (EPA) (2015) state that the post-mining land use(s) must be relevant to the environment in which the mine is located (DMP \& EPA 2015). As the Blue Spec mine tenements overlay the Bonney Downs pastoral station it follows that the appropriate post-mining land use would be open rangeland for pastoral purposes. However, the post-mining land use also needs to be achievable in the context of post-mining land capability (DMP \& EPA 2015), and the legacy left by the historical mining operations means that some areas within the mine site would need to be excluded from this purpose even when remediated and rehabilitated. Further, no topsoil had been retained during previous site clearing, the remaining soils present in the project area are poorly structured and some soil types are potentially dispersive and saline. As a result, the soils present in the project area were unlikely to be a suitable growth medium. This significantly limits the site's revegetation effort which in turn would constrain use of the site for pastoral purposes.

Many mine sites in Western Australia are located in remote areas where public access is unlikely or limited. However, the Blue Spec mine is relatively accessible from the town of Nullagine (Figure 1) and is listed on the Shire of East Pilbara Municipal Heritage Inventory (O'Brien Planning Consultants 1999) as having historical and social significance. Therefore, it is reasonable to expect that visitors to the region could visit the site.

On the basis of the above, it was proposed that the closure objective for Blue Spec would be to create conditions conducive to rehabilitation so that rehabilitated land surfaces, as far as practicable, function in a way that does not adversely impact on the use of the surrounding landscape for pastoral purposes (Bioscope Environmental Consulting Pty Ltd 2013). This objective assumed that it was feasible for rehabilitated land surfaces at the mine to be safe and stable, and be left in a condition that did not result in offsite contamination. However, it was determined that the development of a vegetation cover was 
unlikely to occur across much of the site due to soil limitations (as outlined previously). This would mean that most of the site would not support pastoral grazing but could be left in a condition that did not constrain this land use in adjacent areas. Further work is required to determine if this objective is achievable but sufficient work was conducted initially to allow preliminary engagement with the DMP.

\section{$5 \quad$ Assigning responsibility}

\subsection{Retrospective liability}

In Western Australia, where mining tenure over a site has been held continually by one or a series of organisations or parties, the current tenement holder is responsible for the rehabilitation of historical disturbances irrespective of who created or contributed to the creation of those legacies. However, retrospective liability for new tenement holders is removed when there has been a break in tenure.

The DMP has confirmed that there has been a break in tenure between the historical disturbance within M46/244 and NWR acquiring this mining lease. This means that, with BCG acquiring the lease from NWR, the current tenement holder is not responsible for rehabilitating and closing the Anglo TSF unless this facility is reopened or redeveloped. However, there has been no break in tenure for $M 46 / 115$, so the current tenement holder is required to comply with the MCP guidelines (DMP \& EPA 2015) and rehabilitate and close the site to agreed standards.

In some instances, a mining company may offer to rehabilitate areas of historical disturbance even where there is no legal or other motivation to do so. These offers have merit and should be encouraged but there is concern about the extent of retrospective liability in these situations. An example of the problems that can arise in connection with activities on a historical mine site is the Penn Mine case, which is discussed in Danielson and Nixon (1999). In this case, a local utility district acquired part of the abandoned Penn copper-zinc mine in the United States so that it could build a reservoir on the property. Subsequently, a facility to contain toxic runoff from the mine was constructed by the utility district in conjunction with the state water quality control board. The facility was able to contain the seepage under normal conditions but it overflowed during very rainy periods. As the runoff containment facility did not eliminate all discharges from the site, an environmental group successfully sued the two agencies for discharging pollutants without the appropriate permit. Consequently, these agencies were required to undertake further (and expensive) clean-up of the site despite never being involved in operating the mine (Danielson \& Nixon 1999).

To encourage mining companies to voluntarily contribute funds and expertise to the reclamation of abandoned mines, some provinces in Canada including Ontario and Québec have Good Samaritan policies that encourage mining companies to participate in the clean-up of abandoned mine sites without incurring liability from past operations (Fraser Institute 2012). Initiatives such as this would assist those companies willing to take responsibility for the remediation and rehabilitation of historical disturbances, but who are concerned about incurring retrospective liability for these and other legacies at these sites.

\subsection{Custodial transfer of risk and risk management after tenement relinquishment}

The relinquishment of a company's mine tenement(s) and obligations in relation to a closed mine is strongly influenced by local laws, regulations and guidelines, but it is recognised that the clarity of such conditions may vary widely between jurisdictions, and even between mines in a single jurisdiction (ICMM 2006). Very few mines have been effectively relinquished in Australia or around the world. This lack of systematic relinquishment is often associated with a lack of a formal process or a lack of adequate completion criteria that can comfortably be used to assess whether or not a closed mine has achieve the desired standards.

Relinquishment of a closed mine is influenced by community concern for the site and the regulator's or land recipients' experience and appetite for risk. Even when a company has met all of its rehabilitation and closure obligations, regulators and/or other stakeholders may still be reluctant to allow the mine closure 
process to be finalised and for tenements to be relinquished as liability for any latent impacts then reverts to government and could impact local and possibly regional communities. For example, Botham et al. (2013) report delays in issue of a mine closure certificate for De Beers' The Oaks diamond mine despite the company implementing all relevant national legislation and policy directives and meeting all rehabilitation targets related to integrating the site into the natural environment to ensure mitigation of environmental impacts and social risks), the pit remaining in the state to which regulators agreed at the time of decommissioning, and the agreed post-closure land use being attained. Postponement of a final resolution to ongoing liabilities has resulted in the need for further engagement by De Beers, as well as financial implications, and there is a lack of certainty regarding future land use for any future owners, local communities and regulators (Botham et al. 2013).

Environmental harm can arise or be identified following tenement relinquishment for a number of reasons. For example, the future impact of mining may not have been recognised or could not be foreseen during the period of tenure, the regulator may have failed to adequately enforce environmental management and rehabilitation obligations imposed on a site or to which a mining company had committed, or the regulatory framework may have been ineffective in imposing adequate obligations (Ward 2015). In Western Australia, regulators have the ability to impose rehabilitation and remediation obligations on mining companies through MCP guidelines (DMP \& EPA 2015), and other mechanisms, while the companies hold mining tenure but have limited authority to do so after tenements have been relinquished (Ward 2015). Consequently, the State's ability to uphold the polluter-pays principle decreases significantly if mining tenure has been relinquished.

The polluter-pays principle requires those cause environmental harm to bear the cost of redressing that harm (Ward 2015). Ward (2015) argues that this principle could be upheld more effectively in Western Australia if the regulator could impose secured rehabilitation obligations on a mining company after tenement relinquishment. This author examined the ability for such obligations to be imposed through this State's framework of civil and criminal liability, but concluded that this mechanism is not adequate to uphold the polluter-pays principle and that regulatory reform is required to achieve this objective (Ward 2015).

The environmental, social and economic benefits and legacies that can arise from the mining industry mean that discussions regarding mine closure and long-term liabilities are critical for both the private and public sectors (Botham et al. 2013). A decade ago, the ICMM recognised the need to establish formal relinquishment processes that were accepted by industry, the community and regulators who would be accountable for their implementation. It was suggested that the relinquishment process should comprise clear, measurable and auditable criteria that are agreed by both the company and regulators as early as possible so that they can be incorporated into operational plans and thus are achievable (ICMM 2006). In more recent times, it has also been acknowledged that other stakeholders, such as the post-mining land user or those involved in the custodial transfer of the operation, must also be included in the establishment of the relinquishment criteria. As outlined in ICMM's report on financial assurance (Miller 2005), when an operation has been successfully closed and the site has achieved the desired condition, further liability and financial responsibility associated with the site should be relieved. The key challenge for regulators and the proposed new custodian of an operation is the level of confidence that exists in relation to whether a site will retain the desired condition and thus not become an environmental risk in the future.

\section{Stakeholder perceptions and engagement}

Stakeholder engagement is a key component of closure planning. However, stakeholders often hold conflicting views on what constitutes acceptable closure risks and outcomes. Some stakeholders even insist that rehabilitated land and closed mine sites should be maintenance free (Robertson \& Shaw 1999) and without risk.

There is a need for dialogue regarding the actual environmental and community risks associated with historical sites and what rehabilitation and closure standards to apply. There may also be a need for mining companies to educate stakeholders about the impracticality and cost of the maintenance-free option 
(Robertson \& Shaw 1999). It is important that stakeholders understand the standards that applied during a site's operational phase and what closure outcomes are realistic for a mine with no or limited rehabilitation resource and/or other issues. Stakeholder dialogue for these historical sites should be as open, transparent and inclusive as possible.

To obtain agreement on the best way to proceed with planning and implementing closure of historical sites, it may be necessary to establish a third party facilitated closure committee that includes representatives from key regulators (including the land planning management agency), the proposed new land manager or user, Traditional Owners (were relevant) and technical specialists. This facilitated forum should aim to determine what is a practical outcome for the site, identify appropriate closure standards, including whether or not contemporary standards are achievable, and how best to obtain agreement from all parties on the closure of the site.

\section{Is there another option? Could greater environmental benefits result from another approach?}

It is often the case that operations are required to continue remediation or rehabilitation efforts in an attempt to establish a self-sustaining ecosystem that is compatible with the surrounding environmental or proposed post-mining land use. This often requires the outlay of significant funds, but does not necessarily result in environmental or social benefits and does not guarantee that a mining company will be allowed to relinquish its tenements. Under these circumstances, there is a need to consider alternatives. For example, regulators and other stakeholders could accept that no further improvement is likely and simply allow the mining company to relinquish the mine without further obligation. Under this scenario, the burden of managing existing or latent impacts would rest with governments or communities who may not be sufficiently resourced to address this responsibility. Therefore, relinquishment of a mine in its current condition could be contingent upon the company establishing a trust fund, bond or other financial guarantee to allow the new owner or custodian of the site to address any environmental impacts that materialise over the next period of time (say 50 to 100 years). Alternatively, the company could establish an environmental closure offset that addresses local or regional environmental issues not necessarily associated with the mine itself.

A number of countries have considered, or are considering, the need to stipulate funding to manage long-term and latent mine site impacts. For example, the United Kingdom's Mining Waste Directive requires a financial guarantee that is based on the risk posed by the material being extracted to pay for monitoring and aftercare of a site, with funding required for up to 60 years for facilities managing hazardous extractive waste (Botham et al. 2013). A similar system is being implemented in South Africa, though funding is required for a shorter period (Botham et al. 2013).

If there is little or no opportunity for a mining company to establish a financial guarantee or other similar mechanism (or for governments to impose these) to allow latent impacts to be addressed following tenement relinquishment, implementation of environmental offsets may be possible. In the last 15 years or so, the resource sector, government agencies, environmental non-government organisations and the wider community have realised that not all environmental impacts can be fully addressed by proactive management during design, operation and closure of a resource project (ICMM 2005). To assist in addressing these gaps, companies and regulators have implemented environmental offset activities and regulations.

In 2003, the ICMM agreed to investigate the use of offsets to provide greater social, environmental and economic benefits rather than trying to mitigate all impacts associated with the resource sector (ICMM 2005). Since then, all Australian State and Federal Governments have developed offset policies and guidelines that are used to further reduce environmental impacts not adequately addressed by regulations or company practices. Is it possible that a similar approach could be used for historical mines that are struggling to meet current closure standards while they are safe and stable? The key challenge here is that these mines started before stakeholders and regulators planned for rehabilitation let alone closure, which are now a central aspect to the establishment and operation of a contemporary mine. 
Closure offsets could be used to address other environmental impacts or biodiversity loss such as feral animals, weed infestations, abandoned mines or other forms of land degradation. Is it time to realise that some mine sites will not achieve modern standards and thus continuing to commit resources to achievement that objective does not benefit the environment or the local community? On this basis, and assuming that all environmental legacies can be contained within a site such that no unacceptable offsite impacts occur, stakeholders may be prepared to accept the implementation of offsets at another site or area in lieu of further closure work on a historical site. This would allow alternative and, possibly better, environmental outcomes to be achieved offsite rather than trying to achieve the impossible on a site that was not set up to current-day standards. This will clearly require careful consideration but a closure offsets strategy (Figure 4) may be an appropriate mechanism to allow relinquishment of certain historical mines.

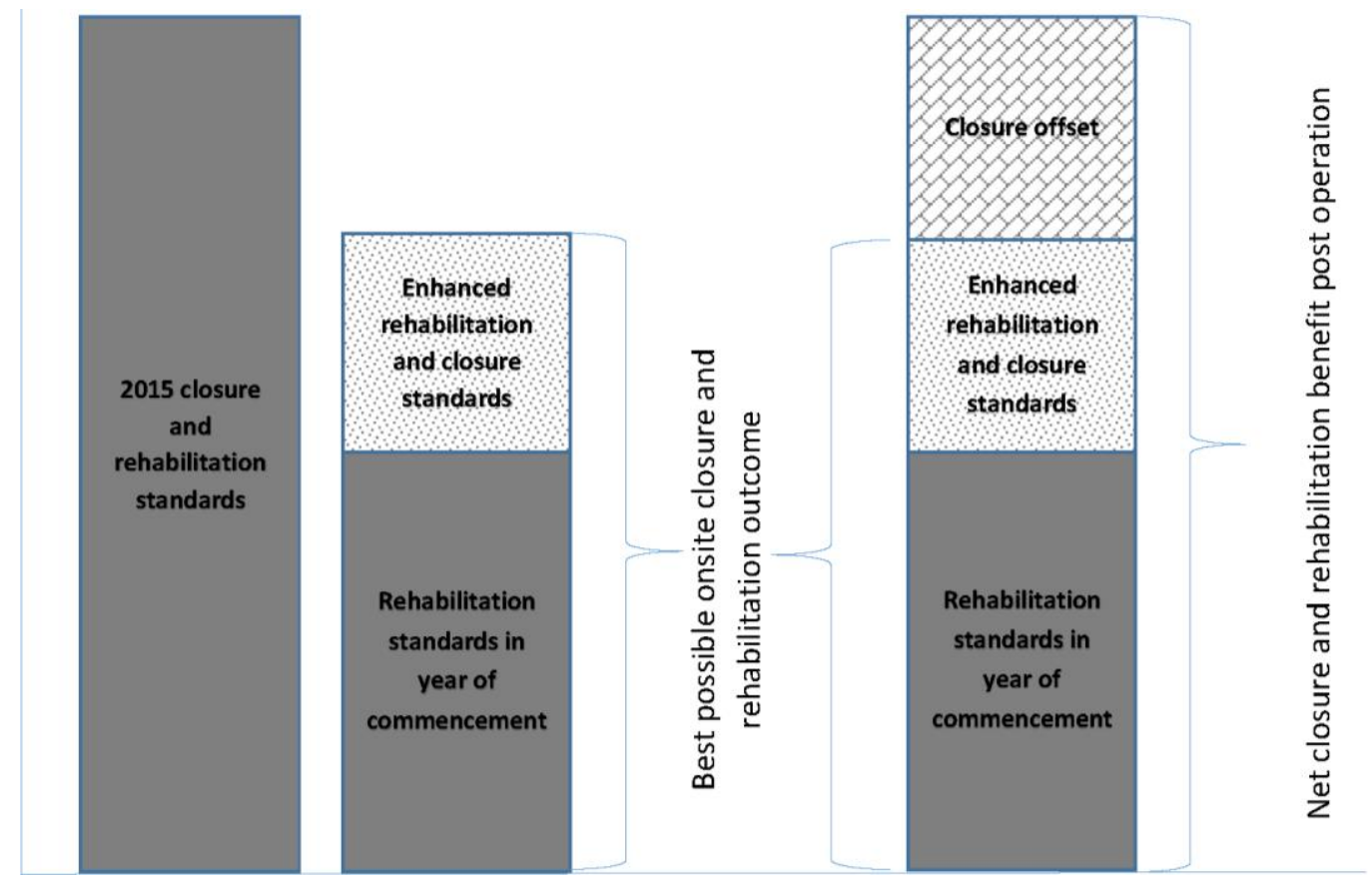

Figure 4 Suggested closure offset strategy for historical mine sites

The imposition of environmental closure offsets related to mine closure and/or financial guarantees or other such mechanisms to fund the management of existing long term or latent impacts will affect a mine's start-up and operational costs. This could reduce project viability but would reduce the mine owner's exposure to risk and achieve a strengthened balance sheet (Botham et al. 2013). Further, these mechanisms provide an opportunity for regulators and other stakeholders to have more influence in the way that a site is managed following tenement relinquishment and could provide greater environmental and/or community benefits not possible while the site was operated as a mine. This would require development of a post-mining sustainable use plan rather than a MCP (Robertson \& Shaw 1999).

\section{Conclusion}

The mining industry can do much to reduce the risk of environmental and social impacts associated with a relinquished mine site. However, it is not realistic to expect that all sites will be able to eliminate all of their environmental and community liabilities prior to tenement relinquishment, or prevent issues arising in the future. This does not mean that mining companies should ignore their responsibilities and that new mines should not be expected to achieve current-day closure standards or best practice, but it is not realistic to expect that historical mine sites established at a time when there was little or no focus on planning for closure can achieve the same standards or meet the same expectations as contemporary mines. In some cases, perpetual care may be the only option (Robertson \& Shaw 1999). In these instances, as discussed in this paper, a different approach is required to address existing and latent impacts associated with historical mine sites. 


\section{Acknowledgement}

The authors gratefully acknowledge Mr John Merity of Northwest Resources Ltd and Mr Simon Pooley of Novo Resources Corporation for allowing the Blue Spec Shear Gold-Antimony Project to be used as a case study for this paper.

Closure planning for the Blue Spec Gold-Antimony Project was conducted by Northwest Resources Ltd and Bioscope Environmental Consulting Pty Ltd with input from URS Australia Pty Ltd, SRK Consulting and Red Rock Engineering. The efforts of these teams are acknowledged and appreciated. We also thank those who reviewed the draft of this paper and provided their constructive comments.

The authors thank CAD Resources for preparing Figures 1 and 2 of this paper.

\section{References}

Bioscope Environmental Consulting Pty Ltd 2013, Blue Spec Gold-Antimony Project Mine Closure Plan, Working draft report prepared for Northwest Resources Limited, Perth.

Botham, N, Bower, G, Vercoe, J \& Lerotholi, N 2013, 'Mine closure liabilities and risk management - minimising the pitfalls in decommissioning policy, in Environment and Society Conference, The Southern African Institute of Mining and Metallurgy Mining.

Danielson, L \& Nixon, M 1999, 'Current regulatory approaches to mine closure in the United States', in A Warhurt \& L Noronha (eds), Environmental Policy in Mining. Corporate Strategy and Planning or Closure, Lewis Publishers, Boca Raton, pp. 311-350.

DER (Department of Environment Regulation) 2014, Assessment and Management of Contaminated Sites. Contaminated Sites Guidelines, Government of Western Australia, Perth.

Didier, C, Van Der Merwe, N, Betournay, M, Mainz, M, Kotyrba, A, Aydan, O, Josien, JP \& Song, WK 2008, Mine Closure and Post-mining Management International State-of-the-Art, International Commission on Mine Closure, International Society for Rock Mechanics.

Didier, C, Van Der Merwe, N, Betournay, M, Mainz, M, Aydan, O, Kotyrba, A, Song, WK \& Josien, J 2009, 'Presentation of the ISRM mine closure state of the art report', in SINOROCK 2009: ISRM-sponsored International Symposium on Rock Characterisation, Modelling and Engineering Design Methods.

DMP \& EPA (Department of Mines and Petroleum \& Environmental Protection Authority) 2015, Guidelines for Preparing Mine Closure Plans, Government of Western Australia, Perth.

Environment and Security Initiative 2005, Mining for Closure: Policies and Guidelines for Sustainable Mining Practice and Closure of Mines, United Nations Environment Programme, viewed 21 August 2015, http://www.grida.no/publications/security/ book/2367.aspx

Fraser Institute 2012, What are abandoned mines?, viewed 22 August 2015, http://www.miningfacts.org/Environment/What-areabandoned-mines/

ICMM (International Council on Mining \& Metals) 2005, Biodiversity Offsets - A Briefing Paper for the Mining Industry, International Council on Mining \& Metals, London.

ICMM (International Council on Mining \& Metals) 2006, Integrated Closure Planning, International Council on Mining \& Metals, London.

Miller, G 2005, Financial Assurance for Mine Closure and Reclamation, International Council on Mining \& Metals, London.

NWR (Northwest Resources Limited) 2015, History, viewed 25 September 2015, http://www.nw-resources.com.au/ project_information/blue_spec_shear_gold_antimony_project/history.phtml

O'Brien Planning Consultants 1999, Municipal Heritage Inventory for the Shire of East Pilbara, Subiaco, Western Australia.

Robertson, AM \& Shaw, SC 1999, 'The concept of custodial transfer of mined land', in IMWA Proceedings 1999, International Mine Waste Association, pp 765-771.

SRK Consulting 2012, Blue Spec Shear Gold-Antimony Project Contaminated Sites Strategic Analysis, Confidential final draft report prepared for Northwest Resources Limited, Perth.

Unger, C 2014, What should we do with Australia's 50,000 abandoned mines?, viewed 26 September 2015, http://theconversation.com/what-should-we-do-with-australias-50-000-abandoned-mines-18197

URS 2012, Blue Spec Shear Gold-Antimony Project Preliminary Site Investigation, Confidential final report prepared for Northwest Resources Limited, Perth.

Ward, C 2015, 'Miners' liability to redress reduced water quantity and quality after mine site closure: A case study of the Collie Coalfields in Western Australia', Environmental and Planning Law Journal (2015) 32 EPL 455, viewed 15 October 2015, http://www.thomsonreuters.com.au/environmental-and-planning-law-journal-online 